\title{
Doenças Emergentes: uma Análise Sobre a Relaçáo do Homem com o seu Ambiente
}

\section{Emerging Illnesses: an analysis about the relation humans have with Environment}

\author{
Jair Antonio de Carvalho ${ }^{1}$ \\ Sandra Regina Farias Teixeira ${ }^{1}$ \\ Márcio Pedrote de Carvalho ${ }^{2}$ \\ Valéria Vieira ${ }^{3}$ \\ Fábio Aguiar Alves ${ }^{3}$
}

\section{Resumo}

Trabalho com o objetivo oportunizar discussão sobre as doenças emergentes e reemergentes e suas relações com as questôes ambientais. Justificando-se pela necessidade de trazer à tona discussóes sobre as doenças emergentes e os fatores que as oportunizaram, o mesmo raciocínio se aplica às doenças reemergentes. Doenças emergentes são doenças que vêm surgindo nos últimos anos ou que já existiam e que vem aumentando sua incidência, ultimamente. O Brasil possui uma grande variedade de ecossistemas, envolvendo tanto da fauna quanto da flora, estando este, sujeito à degradação em função de "grileiros" na busca de riqueza fácil e rápida. Ao tratar de doenças infecciosas emergentes e reemergentes, verificam-se dois focos de atenção: o surgimento ou identificaçáo de novos problemas de saúde e novos agentes infecciosos. A rapidez dos meios de transporte leva estes agentes espalharemse de um continente para outro. Medidas preventivas devem ser tomadas a fim de evitar o aparecimento de novas doenças e o reaparecimento das tidas como erradicadas. Medidas educacionais devem ser aplicadas, a fim de minimizar, se não erradicar o problema das doenças emergentes e reemergentes, garantindo assim uma melhor qualidade de vida

Palavras-chave: Doenças Emergentes e Reemergentes; Ecossistemas; Preservação Ambiental; Medidas Preventivas e Educativas; Relação Homem e Ambiente

\section{Abstract}

This work aims to rise the discussion about emerging and re-emerging illnesses and their relations with environmental questions. Justified by the necessity of bringing up discussions about emerging illnesses and the factors which make them possible, the same argumentation can be applied to re-emerging illnesses. Emerging illnesses are the ones which have been appearing during the last years or which existed before and have increased its occurrence lately. Brazil has a great variety of ecosystems, involving both fauna and flora, being the last one subject to degradation by "grileiros" searching for easy and fast richness. Treating emerging and re-emerging infectious illnesses, two focuses of attention were found: the appearance or identification of new health problems and new infectious agents. The fastness of ways of transport helps those agents to be spread from a continent to another. Preventive measures must be taken in order to avoid the appearance of new illnesses and the re-appearance of the ones considered as eradicated. Educational measures must be applied, in order to minimize, if not eradicate the problem of emerging and re-emerging illnesses, assuring, this way, a better life quality.

Keywords: Dislexy, Emerging and Re-emerging Illnesses; Ecosystem; Environmental Preservation; Preventive and Educative Measures; Human-environment Relation

\footnotetext{
${ }^{1}$ Mestrandos - Mestrado Profissional em Ensino em Ciências da Saúde e do Meio Ambiente - UniFOA ${ }^{2}$ Especializando - Vigilância em Saúde - FMT

${ }^{3}$ Doutores - Mestrado Profissional em Ensino em Ciências da Saúde e do Meio Ambiente - UniFOA
} 


\section{INTRODUÇÁO}

Nos últimos anos, tem-se observado a ocorrência de novas doenças, bem como o reaparecimento de doenças tidas como erradicadas. Essas ocorrências, as chamadas doenças emergentes e reemergentes vêm sendo frequentemente citadas através dos meios de comunicação, informando e alertando a população para os riscos que tais enfermidades podem ocasionar.

Essas infecçóes, em sua grande maioria, são de origem viral. A AIDS é um bom exemplo de uma doença emergente, assim como o Dengue, se aplica como doença reemergente.

Na medida em que as doenças transmissíveis, sujeitas à vigilância, vão reduzindo sua incidência, a importância política dos órgãos de controle também vão diminuindo, podendo chegar até mesmo ao esquecimento por parte do comando das estruturas governamentais.

No Brasil, evidencia-se uma variedade considerável de ecossistemas, com gigantesca diversidade, tanto no tocante a fauna quanto à flora apresentada. Estes ecossistemas encontram-se cada vez mais sujeitos à degradação, em função da ação constante dos "grileiros" em busca riqueza fácil e rápida, sem medir as conseqüências que pode levar à natureza. $\mathrm{O}$ avanço da agricultura e da pecuária nas áreas naturais vem proporcionando contato entre as populaçóes humanas e seus animais domésticos com as populaçôes de animais silvestres no seu habitat. Este contato facilitou a disseminação de agentes infecciosos e parasitários para novos hospedeiros e ambientes. Como conseqüências dessas interaçôes podem ocorrer diversas zoonoses.

O presente trabalho tem como objetivo oportunizar discussão sobre as doenças emergentes e reemergentes e suas relaçôes com as questóes ambientais, despertando nas pessoas, a necessidade de manter uma relação harmoniosa com o ambiente em que vive, alertando para os perigos da convivência do homem e seus animais domésticos com os animais silvestres, tendo em vista problemas sanitários e econômicos causados pela disseminação de agentes patogênicos e enfatizar sobre as medidas preventivas que devem ser tomadas, a fim de se minimizar a ocorrência das doenças emergentes e reemergentes.

Este trabalho se justifica, pela necessidade de trazer à tona, novas discussóes sobre as doenças emergentes, os fatores que oportunizaram o seu aparecimento e que medidas de controle devem ser efetivamente tomadas a fim de minimizar, se não erradicar sua proliferação. $\mathrm{O}$ mesmo raciocínio se aplica às doenças reemergentes, no sentido de que as mesmas não voltem a incidir sobre a população.

\section{DOENÇAS EMERGENTES E SUA DEFINIÇÃO}

Doenças emergentes são doenças que vêm surgindo nos últimos anos ou que já existiam e que vem aumentando sua incidência ultimamente.

Quando se trata de doenças infecciosas emergentes e reemergentes, verificam-se dois principais focos de atenção: o surgimento ou identificação de novos problemas de saúde e novos agentes infecciosos; e a mudança no comportamento epidemiológico de doenças já conhecidas, incluindo a introdução de agentes já conhecidos em novas populaçóes de hospedeiros suscetíveis.

Luna (2002), relata que um número grande de fatores estariam envolvidos na determinação da emergência e reemergência de doenças infecciosas. No sentido de facilitar a discussão estes fatores podem ser agrupados em sete grandes grupos:

- fatores demográficos;

- fatores sociais e políticos;

- fatores econômicos;

- fatores ambientais;

- fatores relacionados ao desempenho do setor de saúde;

- fatores relacionados às mudanças e adaptação dos microorganismos e

- manipulação de microorganismos com vistas ao desenvolvimento de armas biológicas.

A rapidez dos meios de transporte leva portadores a várias áreas do mundo e, devido às condiçóes encontradas nesses ambientes, há a possibilidade destes agentes espalharem-se rapidamente. Vetores (freqüentemente insetos) e portadores não humanos de doenças também foram introduzidos em áreas onde nem existiam previamente (PIGNATTI, 2004).

A possibilidade de alcançar qualquer ponto da terra por transporte aéreo em poucas horas, tem proporcionado o deslocamento de vetores de um continente para outro, bem como o contato direto do homem com áreas remotas, onde existe a possibilidade de haver agente até então desconhecido. Igualmente, a importação de animais pode trazer novos agentes de doença ao contato humano (SCHATZMAYR 2001).

A consolidação de uma nova ordem mundial, na qual a integração das economias de diferentes países tem sido acompanhada pelo rápido aumento da circulação de pessoas e mercadorias, resultou na desagregação de modos de vida tradicionais e na degradação ambiental. Dentro deste contexto, aparecem propostas para uma epidemiologia das doenças emergentes e um sistema global de vigilância sanitária e de doenças (SABROZA 2001). 
Ramos Silva (2008), relata que a própria definição de zoonoses como "doenças ou infecçóes que se transmitem naturalmente, entre os animais vertebrados e o homem, ou vice-versa”, já denota a possível participação dos animais silvestres na manutenção destas doenças na natureza.

A conceitualizaçáo de doença emergente, apesar de muito debatida, não é tarefa muito fácil, por ser necessário considerar o aspecto amplo e dinâmico que a envolve. A exemplo da hantavirose, sua abordagem epidemiológica é bem explorada na área médica, onde o objetivo central é desvendar os aspectos clínicos e terapêuticos da doença. Ênfase deve ser dada à produção científica sobre a referida zoonose, que também tem a contribuição de outras áreas como a Medicina Veterinária e a Biologia. (SCHMIDT, 2007).

Além das doenças cujos agentes etiológicos são desconhecidos, as doenças emergentes incluem velhas doenças que apresentam novos comportamentos epidemiológicos. Uma doença relativamente conhecida que vem merecendo atenção é a infecção pelo vírus da hepatite "B". A presença das doenças emergentes e reemergentes colocam uma série de desafios para a saúde pública em geral e para a epidemiologia, em particular. O primeiro deles diz respeito à biossegurança (BARATA, 1997).

\section{DOENÇAS EMERGENTES MAIS COMUNS E SEUS HISTÓRICOS}

Analisaremos de forma pontual algumas dessas doenças, relatando seu aparecimento histórico, assim como, os malefícios para a população.

A Zoonose ocupa um lugar cada vez mais importante entre os problemas de Saúde Pública no Brasil, tanto nas zonas rurais quanto nas urbanas.

O vírus do Nilo Ocidental (VNO) utiliza aves como reservatórios naturais e mosquitos ornitofílicos como vetores obrigatórios. Este gênero de mosquito tem distribuição cosmopolita, inclui muitas espécies antropofílicas e adaptados ao convívio humano. A transmissáo entre humanos só foi registrado através de transfusão sanguínea e transplante de órgãos.

$\mathrm{O}$ vírus da influenza aviária (VIA), que em formas brandas ou hiperpatógenas, se apresenta como zoonoses entre aves selvagens e domésticas, reservatórios virais que atualmente têm sido uma das grandes preocupaçóes das autoridades sanitárias mundiais, dada a grande capacidade de disseminação (PETRY, 2006).

A malária reapareceu em regióes nas quais havia sido supostamente eliminada e está se espalhando para áreas não afetadas anteriormente. Embora tenham sido utilizados, nos anos 40, inseticidas de ação residual e drogas eficazes para o tratamento da malária, observou-se um aumento do número de casos no Brasil a partir de 1970, com cerca de mais de meio milhão de casos notificados anualmente pelos serviços de saúde. Atribui-se este aumento à maneira pela qual foi ocupada a regiâo da floresta amazônica por projetos agropecuários, pela mineração e construção de grandes usinas hidrelétricas, além da abertura de rodovias, que facilitaram o acesso à região (PIGNATTI, 2004).

Porto (1994), relata que a malária, também chamada impaludismo é uma doença infecciosa causada por um protozoário do gênero Plasmódium e transmitida por um mosquito do gênero Anopheles. O homem é o único reservatório do $P$. falciparum, que entre todos é o causador de maior morbidade.

O cólera, depois de cerca de um século, está reaparecendo na América Latina. Acredita-se que sua reintrodução na América do Sul nos anos de 1990 foi resultado de uma descarga, por um cargueiro, de água de lastro da China nas águas costeiras do Peru. A água carregou o vibrião da cólera, o qual cresceu nas águas enriquecidas com nitrogênio e fósforo provenientes do esgoto e fertilizantes (PIGNATTI, 2004).

Segundo Otto Bier (1994), no Brasil, o coléra foi registrado em 1885, no Amazonas, Pará, Bahia e Rio de Janeiro. Sendo que no estado de São Paulo, tanto na capital quanto no interior foi registrado em 1893.

A febre amarela urbana e seu principal vetor, o mosquito Aedes aegypti, provavelmente espalhou-se da África para a América via comercialização escrava, mas a rapidez com que as mercadorias e as pessoas agora se movem ao redor do globo tem aumentado ainda mais a probabilidade do tráfico dos "agentes patógenos".

A febre amarela é essencialmente doença de primatas, porém com capacidade de alcançar o homem que penetre em áreas endêmicas sem proteção vacinal (SCHATZMAYR, 2001). O número de casos de febre amarela silvestre apresenta-se em contínuo aumento na África. Estima-se a ocorrência de 200.000 casos em 1995. Embora o Brasil possua a maior área enzoótica de febre amarela silvestre do mundo, compreendendo as zonas da mata das regióes Amazônicas e Centro Oeste, tem-se observado uma diminuição da ocorrência da doença nos últimos anos (PIGNATTI, 2004).

A dengue, uma infecção viral também transmitida pelo Aedes aegypti, espalha-se pelo mundo a uma velocidade impressionante. Os casos mais graves da doença, a febre hemorrágica de dengue e a síndrome de choque, estão explodindo. Segundo Pignatti (2004), entre 1982 a 1998, foram notificados no Brasil 1.672.883 casos de dengue clássico. Em relação ao dengue hemorrágico, no período de 
1990 a 1999, ocorreram 888 casos, sendo que destes 39 foram a óbito. As condições de permanência e circulação dos vírus estão fortemente associadas com a densidade e dispersão dos vetores.

A forma de organização do espaço dos centros urbanos, o modo de vida de suas populaçóes e os seus reflexos no ambiente cria as condiçôes para a proliferação dos vetores (principalmente no espaço doméstico). Neste sentido, tanto as populações com más condições sociais ou econômicas, como as de melhores condiçóes, estão sujeitas a adquirir a infecção (PIGNATTI, 2004).

Veronesi (1996), relata que no Brasil e na Colômbia a ocorrência de dengue predominou em pacientes com idade superior a 15 anos. O nosso país ocupa o $5^{\circ}$ lugar na lista de notificaçóes, a maioria dos casos ocorreu durante as epidemias que afetaram os estados do Rio de Janeiro entre 1990 e 1991 e no Ceará em 1994.

A doença de Lyme, que ocorre principalmente nos Estados Unidos, mas há suspeita de casos no Brasil, está relacionada às várias atividades humanas que alteram dramaticamente a ecologia da regiấo. A derrubada das florestas durante séculos anteriores, para dar lugar à agricultura, eliminou os veados e seus predadores da área. As florestas retornaram ao longo do tempo, assim como os veados, mas não seus predadores. Os carrapatos, portadores do agente etiológico da doença de Lyme, a disseminaram para toda a populaçáo de veados. Ao mesmo tempo, casas foram construídas nas proximidades das florestas, levando um maior número de pessoas a serem picadas pelos carrapatos infectados, espalhando-se por diversos estados (PIGNATTI, 2004). Casos da doença de Lyme no Brasil, foram registrados em áreas próximas a vegetaçóes, onde provavelmente habita animais silvestres (Veronesi,1996). Várias pessoas contraíram a doença em derrubadas de matas, outros em visitas a sítios ou fazendas, outros praticando cavalgada ou lidando com cáes infectados por carrapatos ou ainda deitando na grama.

A febre maculosa foi identificada nos estados de São Paulo e Minas Gerais na primeira metade deste século. Os principais vetores são os carrapatos Amblyomma cajennense e o A. Striatum ambos encontrados infectados no homem e no cão, sendo que a espécie cajennense é o que mais ataca o homem no Brasil (OTTO BIER, 1994).

\section{CONCLUSÃO}

Toda modificação do espaço físico ou da paisagem, determina alteraçóes ecológicas na patobiocenose, alterando a circulação do agente infeccioso (SILVA, 1997).

A alteração dos habitats provocados pelas atividades humanas leva a uma modificação nas formas de adaptação dos patógenos. A disseminação de um patógeno humano requer a vulnerabilidade da população. A vulnerabilidade de uma comunidade para um patógeno depende além da virulência e da velocidade de transmissão, da imunidade da população. Portanto, a vulnerabilidade de uma população humana às doenças está sujeita ao estado geral de saúde que é determinado por fatores sócio-econômicos, nutricionais, herança genética e espaço geográfico, acrescido por de outros fatores como: uso de álcool e fumo. Fatores que ditam a imunidade ou exposição à contaminação dessa população.

A degradação ambiental vem contribuindo consideravelmente para o aparecimento ou surgimento de novas doenças. Se o terreno não é favorável, as colonizaçóes não sobrevivem. Se o ambiente é receptivo o patógeno intromissor se prolifera em adaptaçóes de oportunidades para novas espécies.

As modificaçóes ambientais em todos os níveis afetam consideravelmente a distribuição das doenças. Numa escala maior ou menor, as modificaçóes ambientais afetam a disseminação de doenças infecciosas. As intervençóes humanas no ambiente contribuem para o deslocamento de vetores ou de agentes etiológicos atingindo populaçôes assentadas em áreas próximas, atingindo em seguida, áreas periféricas e urbanas como o caso da febre amarela urbana. A ausência de políticas públicas que promovam integração de medidas que visem à promoção da saúde humana incluindo condiçóes ambientais apontam para uma perspectiva ameaçadora para esse início de milênio.

Por meio da análise desses levantamentos bibliográficos, pode-se concluir que cuidar do ambiente como fator de preservação é de extrema importância. Esse cuidado pode evitar que a interação entre humanos e o ambiente, de forma indevida, oportunizando o contato do homem com patógenos comuns ao ambiente silvestre, favoreçam o aparecimento de novas doenças. Assim, as doenças tidas como erradicadas (reemergentes) não voltarão a ser problema de saúde pública.

Portanto, medidas preventivas devem ser tomadas a fim de evitar o aparecimento de novas doenças e o reaparecimento das tidas como erradicadas. Sugerimos aqui, medidas preventivas em educação em saúde, principalmente as que podem ser realizadas através de Centros Universitários. Entendemos, portanto, que a educação em saúde é um processo de troca de conhecimentos entre a população e os profissionais de ensino e saúde, no sentido de complementaridade, construção, desconstrução e reconstrução de saberes. Consideramos, ainda, que nesse processo os sujeitos envolvidos, profissionais e população, são detentores de um acúmulo de conhecimentos, e, cada um precisará dos conhecimentos do outro para poder 
se comunicar e garantir, no final do processo, uma nova aprendizagem. Existem diversos trabalhos em educação e saúde que partem sempre de uma necessidade da população (Moura, et all). Nesses trabalhos, o objetivo seria dar resposta a uma situação identificada após uma pesquisa, de campo, por exemplo. Sendo assim, trabalharíamos com a população afetada, conhecimentos científicos específicos.

Medidas educacionais devem ser aplicadas, a fim de minimizar, se não erradicar o problema das doenças emergentes e reemergentes, garantindo assim uma melhor qualidade de vida, com mais saúde, agregando mais anos de vida, e o que é mais importante, uma vida mais feliz.

\section{BIBLIOGRAFIA}

BARATA, R. C. B.; O desafio das doenças emergentes e a revalorização da epidemiologia descritiva. Rev. de Saúde Pública. Vol. 31, n. 5, São Paulo; oct. 1997.

LUNA, E. J. A.; A emergência das doenças emergentes e as doenças infecciosas emergentes e reemergentes no Brasil. Rev Brasileira de Epidemiologia. Vol. 5, n. 3, São Paulo; Dec. 2002.

MOURA, A.A.G.; ARAÚJO, A. L.; DUARTE, A.P. V. E DUARTE, M. S. M. Cadernos de Saúde, e Extensão Universitária, Universidade Federal de Pernambuco. Disponível em http://www.proext.ufpe.br/cadernos/saude/ educa.htm acessado em 23/09/2008.

OTTO BIER, G.; Microbiologia e Imunologia. 30 ed. Melhoramentos, São Paulo; 1994.

PETRY, R., PETER, A. S., GUADAGNIN, D. L., Avifauna do Rio Grande do Sul e doenças emergentes: conhecimento atual e recomendaçóes para vigilância ornitológica da Influenza Aviária e da Febre do Nilo Ocidental. Rev. Brasileira de Ornitologia, n.14, Ano 3, p. 269-277, Set. 2006.

PIGNATTI, M. G., Saúde e Ambiente: as doenças emergentes no Brasil. Rev. Ambiente \& Sociedade, vol.7, n.1, Campinas, Jan./June 2004.

PORTO, C. C.; Semiologia Médica., 2 ed., Guanabara Koogan S. A., Rio de Janeiro; 1994.

RAMOS SILVA, J. C., Zoonoses e Doenças Emergentes Transmitidas por Animais Silvestres, Associaçáo Brasileira de Veterinários de Animais Selvagens -
ABRAVAS, 2004, Disponível em www.abravas.org.br Acessado em 05/04/2008.

SABROZA, P. C.; TOEWS, D. W.; Doenças emergentes, sistemas locais e globalização. Cadernos de Saúde Pública. Vol. 17, suppl, Rio de Janeiro; 2001.

SCHATZMAYR, H. G.; Viroses emergentes e reemergentes. Cadernos de Saúde Pública. Vol. 17, suppl, Rio de Janeiro; 2001.

SCHMIDT, R. A. C., A construção do conhecimento do indivíduo no processo de sensibilização-conscientizaçãoação sobre a hantavirose e a oportunidade para o controle e a prevençáo de zoonoses emergentes: a experiência da hantavirose em Santa Catarina, Rev. Saúde e Sociedade, vol.16, n. 3, São Paulo, Sept./Dec. 2007.

SCHMIDT, R. A. C., A questão ambiental na promoção da saúde: uma oportunidade de ação multiprofissional sobre doenças emergentes, Rev. de Saúde Coletiva, vol.17, n. 2, Rio de Janeiro, 2007.

SILVA, J. L., O conceito de espaço na epidemiologia das doenças infecciosas, Rev. Cadernos de Saúde Pública, vol.13, n. 4, Rio de Janeiro, Oct./Dec. 1997.

VERONESI, R., FOCACCIA, R.; TratadodeInfectologia., Ateneu, São Paulo; 1996.
Endereço para Correspondência:

$$
\begin{array}{r}
\text { Jair Antonio de Carvalho } \\
\text { carvalho@superonda.com.br } \\
\text { Sandra Regina Farias Teixeira } \\
\text { sandrafteixeira@yahoo.com.br } \\
\text { Mestrado Profissional em Ensino emCiências da } \\
\text { Saúde e do Meio Ambiente } \\
\text { Centro Universitário de Volta Redonda } \\
\text { Campus Três Poços } \\
\text { Av. Paulo Erlei Alves Abrantes, no 1325, } \\
\text { Três Poços - Volta Redonda / RJ } \\
\text { CEP: 27240-560 }
\end{array}
$$

